DOI:10.5216/cab.v11i3.5122

\title{
EFEITO DAS CONDIÇÕES REPRODUTIVAS E CLIMÁTICAS NA PRODUÇÃO DE EMBRIÕES DE CABRAS BOER SUPEROVULADAS
}

\author{
Sildivane Valcácia Silva, ${ }^{1}$ Gustavo Ferrer Carneiro, ${ }^{2}$ Maria Madalena Pessoa Guerra, ${ }^{3}$ \\ Oswaldo Christiano Gomes Neto, ${ }^{4}$ André Mariano Batista ${ }^{5}$ e Áurea Wischral ${ }^{6}$ \\ 1. Pós-graduanda da UFRPE. E-mail: sildivane@yahoo.com.br \\ 2. Professor doutor da Universidade Federal Rural de Pernambuco em Fisiologia e Reprodução Animal \\ 3. Professora doutora da Universidade Federal Rural de Pernambuco de Andrologia e Biotecnologia da Reprodução \\ 4. Médico veterinário autônomo \\ 5. Pós-graduando da UFRPE \\ 6. Professora doutora da Universidade Federal Rural de Pernambuco em Obstetrícia Veterinária.
}

\section{RESUMO}

Desenvolveu-se este estudo para avaliar os efeitos das condições reprodutivas (multíparas ou nulíparas) e climáticas (período seco ou chuvoso) sobre o número e qualidade de embriões colhidos de cabras da raça Boer superovuladas. Cinquenta fêmeas caprinas, sendo 33 multíparas e 17 nulíparas, foram submetidas à sincronização do estro com o auxílio de CIDR ${ }^{\circledR}$, durante onze dias, e superovuladas com 250UI de FSH-p. Observaram-se as fêmeas quanto ao estro e realização de cobertura a intervalos de doze horas, após a remoção dos CIDR ${ }^{\circledR}$. Os embriões foram colhidos seis dias após a última cobertura, por via transcervical. Não houve diferença significativa $(\mathrm{P}>0,05)$ entre o número médio de estruturas e embriões viáveis recuperados das multíparas ou nulíparas. O número médio de estruturas e embriões viáveis recuperados de doadoras multíparas não diferiu significativamente $(\mathrm{P}>0,05)$ entre os períodos seco e chuvoso. $\mathrm{O}$ número médio de estruturas e de embriões viáveis, classificados como G1, recuperados de doadoras nulíparas foi maior $(\mathrm{P}<0,05)$ no período chuvoso que no período seco. Conclui-se que a condição climática, neste experimento, não teve efeito sobre a produção embrionária de fêmeas multíparas, entretanto as nulíparas foram mais sensíveis ao período seco, apresentando redução no número e qualidade dos embriões recuperados.

PALAVRAS-CHAVES: Cabras, embrião, estresse térmico.

ABSTRACT

\section{EFFECT OF REPRODUCTIVE AND CLIMATIC CONDITIONS ON THE PRODUCTION OF EMBRYOS OF SUPEROVULATED BOER DOES}

This study was conducted to evaluate the effect of the reproductive (multiparous or nulliparous) and climatic (dry or rainy period) conditions on the number and quality of embryos collected from Boer does. Fifty does, being 33 multiparous and 17 nulliparous, were synchronized for oestrus with CIDR $®$ devices for a period of 11 days and superovulated with 250UI of FSH-p. The animals were observed for oestrous behaviour at $12 \mathrm{~h}$ intervals, after CIDR ${ }^{\circledR}$ withdrawal. Does were mated and six days later flushed transcervically to recover the embryos. There was no significant difference $(\mathrm{P}>0.05)$ among the average number of structures and viable embryos recovered from the multiparous and nulliparous females. The average number of structures and viable embryos recovered from multiparous does had no significant difference $(\mathrm{P}>0.05)$ between dry and rainy periods. The average number of structures and viable embryos classified as G1 recovered from nulliparous was lower $(\mathrm{P}<0.05)$ in the dry period than in the rainy period. It could be concluded that the climatic condition did not affect the embryonic production of multiparous females, however the nulliparous were more sensitive to the dry period, presenting reduction in the number and quality of the collected embryos.

KEYWORDS: Does, embryo, thermal stress. 


\section{INTRODUÇÃO}

Nos últimos anos a demanda por raças caprinas, com características superiores como os caprinos Boer, tem causado aumento no movimento internacional de embriões caprinos entre países e continentes (GREYLING et al., 2002).

A transferência de embriões (TE) tem o potencial para aumentar o desempenho reprodutivo de doadoras geneticamente superiores, especialmente quando os animais estão em alta demanda (LEHLOENYA et al., 2008). De maneira a realizar a aplicação comercial desta técnica, é necessário um contínuo suprimento de embriões de boa qualidade durante o ano. Entretanto, diversos fatores limitantes afetam os resultados da TE, como raça, idade, estado reprodutivo, condição climática e nutricional (GONZÁLEZ-BULNES et al., 2004).

A cabra pode se apresentar como poliéstrica estacional ou contínua. Nas regiões tropicais, as mudanças de fotoperíodo são mínimas e, consequentemente, a estacionalidade reprodutiva em pequenos ruminantes é pouco observada, dependendo principalmente de fatores como alimentação e condições térmicas (FREITAS \& LOPES JR., 2002). A distribuição da precipitação pluvial ao longo do ano na região Nordeste do Brasil delimita duas diferentes épocas, seca e chuvosa, que influem no desempenho reprodutivo da fêmea caprina, variando conforme a raça (MORAIS et al., 2008).

Fêmeas jovens têm sido utilizadas em programas de TE visando maximizar o seu aproveitamento reprodutivo, bem como aumentar o número de produtos geneticamente superiores (BALDASSARRE \& KARATZAS, 2004). No entanto, a utilização de fêmeas nulíparas em TE deve ser avaliada, pelo fato de apresentarem imaturidade do aparelho reprodutivo, resultando na produção de gametas malformados (SILVA \& ARAÚJO, 2000) e, consequentemente, no baixo potencial de desenvolvimento embrionário in vivo e in vitro (REVEL et al., 1995).

Este estudo teve como objetivo avaliar os efeitos das condições reprodutivas (multíparas ou nulíparas) e climáticas (seca ou chuvosa) sobre o número e a qualidade de embriões colhidos de cabras Boer superovuladas.

\section{MATERIAL E MÉTODOS}

Desenvolveu-se o estudo em um rebanho comercial, localizado na cidade de Gravatá, estado de
Pernambuco, a 08 $12^{\circ}$ '04" de latitude Sul e a 35'33'53' de longitude Oeste, com altitude de 447 metros acima do nível do mar. O índice pluviométrico médio anual varia entre 380 e $760 \mathrm{~mm}^{3}$, com ocorrência de chuvas principalmente entre os meses de março e agosto; a temperatura média anual é de $26^{\circ} \mathrm{C}$, com máxima de $35^{\circ} \mathrm{C}$ e mínima de $14{ }^{\circ} \mathrm{C}$, caracterizando-se por clima tropical com estação seca, apresentando aumento de umidade relativa do ar e temperatura nos meses de novembro a fevereiro.

Durante o período de estudos, realizou-se acompanhamento da condição climática através da análise dos dados cedidos pelo Laboratório de Meteorologia de Pernambuco (LAMEPE), pertencente ao Instituto de Tecnologia de Pernambuco (ITEP). Considerouse período seco aquele cujo índice pluviométrico foi inferior a $50 \mathrm{~mm}^{3}$ e período chuvoso quando superior a $50 \mathrm{~mm}^{3}$.

Utilizaram-se cinquenta fêmeas Boer, sendo 33 multíparas ( $n=17$ seco; $n=16$ chuvoso), com idade entre 20 e 48 meses, peso médio de $71,3 \mathrm{~kg}$ e histórico reprodutivo de até cinco partos fisiológicos, e $17 \mathrm{nu}-$ líparas ( $\mathrm{n}=8$ seco; $\mathrm{n}=9$ chuvoso), apresentando entre dez e 1doze meses, com peso médio de $57,9 \mathrm{Kg}$. As fêmeas foram mantidas em sistema de criação semiextensivo, permanecendo em piquetes de capim-pangolão (Paspalum sp.) durante o dia e agrupadas à noite em apriscos de chão batido, onde eram suplementadas a cocho com $500 \mathrm{~g}$ de ração balanceada por animal, além de sal mineral e água ad libitum. Nos meses caracterizados como período seco, as fêmeas recebiam capim picado (Pennisetum purpureum) no cocho, duas vezes ao dia, juntamente com a ração.

As fêmeas tiveram o estro sincronizado com o auxílio de dispositivos intravaginais (CIDR ${ }^{\circledR}$, Pfizer, Brasil), inseridos por um período de onze dias. O tratamento superovulatório foi iniciado 48 horas antes da remoção do CIDR, utilizando-se uma dose total de 250UI de FSH-p (Pluset ${ }^{\circledR}$, Hertape-Calier, Brasil), divididas em seis aplicações intramusculares, em doses decrescentes com intervalo de doze horas. Doze horas após a remoção dos dispositivos, as fêmeas foram observadas quanto ao sinal de estro e realização de cobertura, duas vezes ao dia, a intervalo de doze horas, até não mais aceitarem a monta.

Para cobertura foram utilizados quatro reprodutores da raça Boer, com idades entre 24 e 60 meses, 
mantidos em sistema intensivo em aprisco de chão batido e alimentados exclusivamente a cocho com feno de capim tífton (Cynodon spp.), $800 \mathrm{~g}$ de concentrado por animal, além de sal mineral e água ad libitum.

Os embriões foram colhidos no sexto dia após a última cobertura, por via transcervical, como relatam SUYADI et al. (2000). Administrou-se PGF2 $\alpha$, na dose de $0,3 \mathrm{~mL}$ (Ciosin ${ }^{\circledR}$, Schering-Plough, Brasil), vinte horas antes do procedimento de lavagem uterina nas fêmeas. Ambos os cornos uterinos foram lavados por dez infusões consecutivas de $20 \mathrm{~mL}$ de meio de lavagem (DMPBS-FLUSH ${ }^{\circledR}$, Nutricell, Brasil) acrescidos de $1 \%$ de solução de manutenção (EMCARE $\AA$, ICPBio, Brasil). O meio de lavagem recuperado foi pesquisado e avaliado sob estereomicroscópio para identificar o número total de estruturas colhidas. Classificaram-se os embriões quanto ao seu estádio de desenvolvimento e qualidade (grau 1 - massa embrionária simétrica e esférica, com blastômeros individuais uniformes em tamanho, cor e densidade; grau 2 - irregularidades moderadas na forma geral da massa embrionária ou no tamanho, cor e densidade das células individuais; grau 3 - irregularidades maiores na forma da massa embrionária, em relação ao tamanho, cor e densidade das células individuais; grau 4 - morto ou degenerado), segundo os padrões da Sociedade Internacional de Transferência de Embriões (IETS, 1998).

A análise estatística foi realizada utilizando-se o delineamento experimental inteiramente casualizado (DEIC), no esquema fatorial 2 x 2 (duas condições reprodutivas e duas estações do ano) e análise de variância (ANOVA) para o efeito da condição reprodutiva e da estação do ano e a interação destes com o número de embriões colhidos e de embriões viáveis. No grupo de dados em que se obteve valor igual a zero, eles foram submetidos à transformação $(\sqrt{ } \mathrm{x}+1)$ de acordo com REIS (2003).

\section{RESULTADOS E DISCUSSÃO}

As taxas de recuperação do lavado uterino dos grupos de cabras multíparas (90,3\%) e nulíparas $(88,7 \%)$ não apresentaram diferença significativa $(\mathrm{P}>0,05)$, demonstrando que a condição reprodutiva não interferiu na passagem e na manipulação do catéter ou na recuperação do meio de lavagem. Esses resultados divergem daqueles anteriormente relatados por ANDROUKOVITCH et al. (2002), ao reportarem valores insatisfatórios após tentativa de recuperar embriões de fêmeas nulíparas da raça Boer, ressaltando a dificuldade de manipulação e avanço do catéter no lúmen uterino, a necessidade de força para infundir o meio, assim como observação frequente de sangue no líquido recuperado.

No entanto, neste estudo constatou-se refluxo do meio de lavagem por via transcervical em algumas fêmeas multíparas, sendo necessário reduzir o volume do meio infundido. Este fato foi observado com maior frequência em fêmeas mais velhas e pode ser atribuído ao relaxamento da cérvice decorrente de partos anteriores.

Não foi observada diferença significativa $(\mathrm{P}>0,05)$ entre o número médio de estruturas e embriões viáveis recuperados das fêmeas multíparas e nulíparas, independente da estação do ano. Todavia, estes resultados diferem dos relatos de SUYADI et al. (2000), utilizando fêmeas nulíparas da raça Boer, e de AX et al. (2005), usando novilhas da raça Holandesa, ao observarem taxas de recuperação embrionária insatisfatórias nas fêmeas jovens. No entanto, os resultados deste estudo corroboram o sucesso da superovulação de fêmeas caprinas pré-púberes e púberes reportado por SALLES et al. (2000) e MAJUMDAR et al. (1990), os quais obtiveram embriões de boa qualidade que resultaram em crias após serem transferidos para as receptoras.

O número médio de estruturas e embriões viáveis recuperados de doadoras multíparas não diferiu significativamente $(\mathrm{P}>0,05)$ entre os períodos seco e chuvoso (Tabela 1). Estes resultados ratificam os relatos de LEHLOENYA et al. (2008), ao evidenciarem não haver diferença significativa no número total de estruturas e de embriões transferíveis, recuperados de cabras Boer durante as estações reprodutiva e não reprodutiva. Entretanto, esses resultados contradizem achados anteriores em algumas raças caprinas, em que a estação do ano tem grande efeito nas taxas de produção e recuperação embrionária. Esse fato tem sido demonstrado pelo alto número total de embriões recuperados durante a estação reprodutiva, quando comparado à estação não reprodutiva (GONZALEZBULNES et al., 2003).

O número médio de estruturas e embriões viáveis, classificados como $\mathrm{G} 1$, recuperados de doadoras 
nulíparas (Tabela 1) foi significativamente menor $(\mathrm{P}<0,05)$ no período seco do que no período chuvoso. A redução no número e na qualidade dos embriões colhidos de cabras nulíparas durante o período seco pode ser atribuída à temperatura ambiental, uma vez que foram constatados, em média, $35^{\circ} \mathrm{C}$ durante o dia e $20^{\circ} \mathrm{C}$ à noite, com variação de $15^{\circ} \mathrm{C}$ em um mesmo dia. Essa diferença na temperatura pode ter determinado estresse térmico e desconforto aos animais jovens, corroborando os relatos de BRASIL et al. (2000), ao afirmarem que o fornecimento de alimentos com qualidade e quantidade satisfatórias não minimiza o desconforto térmico dos animais, reduzindo a produção de leite e os parâmetros reprodutivos. Da mesma forma, os achados neste experimento ratificam aqueles observados em fêmeas bovinas, em que se evidenciou diminuição no número e na qualidade dos embriões colhidos após estresse calórico (DEMÉTRIO, 2006).

TABELA 1. Número de embriões colhidos (NEC) e classificados como graus 1, 2 e 3, obtidos de cabras multíparas e nulíparas da raça Boer submetidas a tratamento superovulatório e criadas na região Agreste do Estado de Pernambuco, de acordo com a condição climática

\begin{tabular}{llcccc}
\hline \multirow{2}{*}{ Fêmea } & Estação & \multicolumn{4}{c}{ Qualidade embrionária } \\
\cline { 3 - 6 } & & $\begin{array}{c}\text { NEC } \\
\text { Média } \pm d p)\end{array}$ & $\begin{array}{c}\text { G1 } \\
\text { (Média } \pm d p)\end{array}$ & Gédia \pm dp) & G3 \\
Multípara & Chuvosa & $8,7 \pm 7,9$ & $5,1 \pm 5,7$ & $1,9 \pm 4,9$ & $0,5 \pm 1,3$ \\
& Seca & $10,4 \pm 12,7$ & $5,5 \pm 7,9$ & $2,4 \pm 4,3$ & $0,6 \pm 1,7$ \\
Nulípara & Total & $9,55 \pm 10,3$ & $5,3 \pm 6,8$ & $2,15 \pm 4,6$ & $0,6 \pm 1,5$ \\
& Chuvosa & $12,6 \pm 13,1^{\text {a }}$ & $7,1 \pm 9,1^{\text {a }}$ & $1,8 \pm 2,7$ & $0,2 \pm 0,8$ \\
& Seca & $4,5 \pm 5,7^{\mathrm{b}}$ & $1,4 \pm 2,2^{\mathrm{b}}$ & $0,9 \pm 1,9$ & $1,9 \pm 4,5$ \\
& Total & $8,55 \pm 9,4$ & $4,25 \pm 5,6$ & $1,4 \pm 2,3$ & $1,1 \pm 2,6$ \\
\hline
\end{tabular}

$\mathrm{dp}=$ Desvio padrão. Letras minúsculas diversas na mesma coluna indicam diferença $(\mathrm{P}<0,05)$ entre estação climática, de uma mesma condição reprodutiva.

OZAWA et al. (2005) observaram que o estresse térmico durante o recrutamento folicular compromete severamente o crescimento de folículos de tamanho médio para a ovulação, e que esses efeitos estão associados à redução do número de receptores de hormônio luteinizante (LH) e da atividade de síntese de estradiol nos folículos, em cabras expostas a estresse térmico $\left(36{ }^{\circ} \mathrm{C}\right.$ e $70 \%$ de umidade). Isso que pode justificar o menor número de embriões colhidos no período seco nas cabras nulíparas da raça Boer deste estudo.

Sob condições de estresse térmico, as cabras ingerem maior quantidade de água, favorecendo a dilatação rumenal, a sensação de saciedade e a diminuição do consumo de ração (AGUIAR et al., 2007), o que pode ocasionar redução dos níveis energéticos e proteicos necessários às fêmeas doadoras de embrião. Além disso, o período quente afeta o transporte de sêmen através do útero, reduzindo a taxa de fertilização e o número de embriões recuperados, assim como aumentando a quantidade de estruturas não fertilizadas ou degeneradas, conforme foi relatado por MONTY \&
RACOWSKY (1987). Essa condição pode ter afetado os resultados das fêmeas nulíparas deste estudo, uma vez que o efeito negativo do estresse térmico pode ter sido amenizado nas fêmeas multíparas em virtude da adaptação desses animais a mudanças climáticas do ambiente em que estão inseridas (EALY et al., 1993).

Outro fator que pode ter influenciado no número e na qualidade dos embriões recuperados é a posição hierárquica do animal no rebanho, uma vez que fêmeas mais velhas brigam por posições de hierarquia dentro do grupo, alimentando-se primeiro ou ingerindo maior quantidade de concentrado do que as mais novas (ROSA \& BRYANT, 2003). Esse comportamento animal pode refletir na elevação da taxa de ovulação das fêmeas multíparas em comparação às nulíparas e, consequentemente, na resposta embrionária do programa de superovulação observadas neste experimento.

Diferentemente, UNGERFELD et al. (2007) relataram que a hierarquia social não afeta a resposta a tratamentos superovulatórios quanto ao número de 
corpos lúteos ou à qualidade dos embriões colhidos durante a estação reprodutiva. Entretanto, durante a estação não reprodutiva, a posição hierárquica pode influenciar no número de corpos lúteos obtidos. São necessários outros estudos objetivando esclarecer os fatores envolvidos nesse processo, como os efeitos do estresse calórico e da dominância social sobre os rendimentos na produção de embriões de fêmeas caprinas.

\section{CONCLUSÃO}

Com base nos resultados, conclui-se que a condição climática, no referido estudo, não teve efeito sobre a produção embrionária de fêmeas multíparas, entretanto as fêmeas nulíparas foram mais sensíveis ao período seco, apresentando redução no número e qualidade dos embriões recuperados.

\section{REFERÊNCIAS}

AGUIAR, F.C.; LEITE, E.R.; ELOY, A.M.X. Impactos do estresse sobre a produção animal. Sobral: Embrapa Caprinos, 2007. 26 p. (Documentos/Embrapa Caprinos, ISSN 1676-7659; 70). Disponível em: http://www.cnpc.embrapa.br/doc70.pdf

ANDROUKOVITCH, J. L.; KOZICKI, L. E.; KOZEMJAKIM, D. A.; ABREU, R. M.; ÑUNEZ, C. Coleta de embriões caprinos com sonda uretral humana. Archives of Veterinary Science, v. 7, n. 1, p. 37-41, 2002.

AX, R.L.; ARMBURUST, S.; TAPPAN, R.; GILBERT, G.; OYARZO, J.N.; BELLIN, M.E.; SELNER, D.; McCAULEY, T.C. Superovulation and embryo recovery from peripubertal Holstein heifers. Animal Reproduction Science, v. 85, p. $71-80,2005$.

BALDASSARRE, H.; KARATZAS, C.N. Advances assisted reproduction technologies (ART) in goats. Animal Reproduction Science, v. 82-83, p. 255-266, 2004.

BRASIL, L.H.A.; WECHESLER, F.S.; BACCARI JR, F.; GONÇALVES, H.C.; BONASSI, I.A. Efeitos do estresse térmico sobre a produção, composição química do leite e respostas termorreguladoras de cabras da raça Alpina. Revista Brasileira de Zootecnia, v. 29, p. 1632-1641, 2000.

DEMÉTRIO, D. G. B.; RODRIGUES, C.A.; SANTOS, R. M.; DEMÉTRIO, C. G. B.; CHIARI, J.R.; VASCONCELOS, I. L. M. Fatores que afetam a taxa de concepções após inseminação artificial ou transferência de embriões em vacas holandesas em lactação. Acta Scientiae Veterinariae, v. 34, Supl. 1, p. 293, 2006.
EALY, A.D.; DROST, M.; HANSEN, P.J. Developmental changes in embryonic resistance to adverse effects of maternal heat stress in cows. Journal of Dairy Science, v. 76, p. 2899-2905, 1993.

FREITAS, V.J.F.; LOPES JÚNIOR, E.S. Controle do estro e da ovulação em caprinos. In: GONSALVES, P. B. D. et al. Biotécnicas aplicadas à reprodução animal. São Paulo: Varela, 2002. p. 57-68.

GONZÁLEZ-BULNES, A.; BAIRD, D. T.; CAMPBELL, B. K.; COCERO, M. J.; GARCIA-GARCIA, R. M.; INSKEEP, E. K.; LÓPEZ-SEBASTIAN, A.; MENEILLY, A. S.; SANTIAGO-MORENO, J.; SOUZA, C. J. H.; VEIGA-LÓPEZ, A. Multiple factors affecting the efficiency of multiple ovulation and embryo transfer in sheep and goats. Reproduction, Fertility and Development, v. 16, p. $415-420,2004$.

GONZÁLEZ-BULNES, A.; CARRIZOSA, J. A.; DIAZ-DELFA, C.; GARCIA-GARCIA, R. M.; URRUTIA, B.; SANTIAGOMORENO, J.; COCERO, M. J.; LÓPEZ-SEBASTIAN, A. Effects of ovarian follicular status on superovulatory response of dairy goats to FSH treatment. Small Ruminant Research, v. 48, n. 1, p. 9-14, 2003.

GREYLING, J.P.C.; Van der NEST, M.; SCHWALBACH, L. M. J.; MULLER, T. Superovulation and embryo transfer in South African Boer and Indigenous feral goats. Small Ruminant Research, v. 43, p. 45-51, 2002.

IETS. Manual da Sociedade Internacional de Transferência de Embriões. International Embryo Transfer Society. 3. ed. São Paulo: SBTE, 1998. 180 p. Disponível em: <www.iets. org/3rdEditionManualOrdemForm.pdf>

LEHLOENYA, K. C.; GREYLING, J. P. C.; GROBLER, S. Effect of season on the superovulatory response in Boer goat does. Small Ruminant Research, v. 78, n. 1-3, p. 74-79, 2008.

MAJUMDAR, A. C.; MOGHA, I. V.; ANSARJ, M. R. Successful superovulation in prepubertal Barbari goats. Indian Journal of Animal Science, v. 60, p. 1304-1306, 1990.

MONTY, D. E. JR; RACOWSKY, C. In vitro evaluation of early embryo viability and development in summer heat-stressed superovulated dairy cows. Theriogenology, v. 28, p. 451-465, 1987.

MORAIS, D. A. E. F.; LIMA, F. R. G.; VASCONCELOS, A. M.; LIMA, P. O.; MORAIS, J. H. G. Manifestação de estro, fertilidade e desempenho reprodutivo de cabras leiteiras de diferentes raças em ambiente quente. Revista Caatinga, v. 21, n. 2, p. 62-67, 2008.

OZAWA, M.; TABAYASHI, D.; LATIEF, T.A.; SHIMIZU, T.; OSHIMA, I.; KANAI, Y. Alterations in follicular dynamics and steroidogenic hability induced by heat stress during follicular recruitment in goats. Reproduction, v. 129, p. 621-630, 2005. 
REIS, J.C. Estatística aplicada à pesquisa em Ciência Veterinária. Olinda: Luci Artes Gráficas, 2003. 651p.

REVEL, F.; MERMILLOD, P.; PEYNOT, N.; RENARD, J. P.; HEYMAN, Y. Low developmental capacity of in vitro matured and fertilized oocytes from calves compared with that of cows. Journal of Reproduction and Fertility, v. 103, p. 115-120, 1995.

ROSA, H. J. D.; BRYANT, M. J. Seasonality of reproduction in sheep. Small Ruminant Research, v. 48, n. 3, p. 155-171, 2003.

SALLES, H. O.; SANTOS, D. O.; SIMPLÍCIO, A. A. Superovulação em fêmeas caprinas pré-púberes e púberes da raça AngloNubiana. Ciência Animal, v. 10, supl. 1, p. 137-138, 2000.
SILVA, F. L. R.; ARAÚJO, A. M. Desempenho produtivo em caprinos mestiços no semi-árido do Nordeste do Brasil. Revista Brasileira de Zootecnia, v. 29, p. 1028-1035, 2000.

SUYADI, SOHNREY, B.; HOLTZ, W. Transcervical embryo collection in Boer goats. Small Ruminant Research, v. 36, n. 2, p. 195-200, 2000.

UNGERFELD, R.; GONZÁLEZ-PENSADO, S.; DAGO, A.L.; VILARIÑO, M.; MENCHACA, A. Social dominance of female dairy goats and response to oestrous synchronization and superovulatory treatments. Applied Animal Behaviour Science, v. 105, n. 1-3, p. 115-121, 2007. 